\title{
Evaluation of post partum intrauterine contraceptive device versus interval intrauterine contraceptive device insertion
}

\author{
Hiral P. Godhani*, Dhaval K. Patel
}

Department of Obstetrics and Gynecology, GMERS Medical College and Hospital, Ahmedabad, Gujarat, India

Received: 13 June 2019

Accepted: 09 July 2019

*Correspondence:

Dr. Hiral Godhani,

E-mail: hpgodhani@gmail.com

Copyright: () the author(s), publisher and licensee Medip Academy. This is an open-access article distributed under the terms of the Creative Commons Attribution Non-Commercial License, which permits unrestricted non-commercial use, distribution, and reproduction in any medium, provided the original work is properly cited.

\begin{abstract}
Background: Family planning is important not only for population stabilization, but it has been increasingly recognized as central tool to improve maternal and neonatal health. Aim of current study was to compare interval and post partum intrauterine contraceptive device (IUCD) insertion in terms of effectiveness and safety.

Methods: This was a prospective observational cohort study, done in the department of Obstetrics and Gynecology, GMERS Medical College, Sola, Ahmedabad, from August 2015 to April 2017 was taken for evaluation. 80 women in each group who were inserted IUCD after delivery and in the interval period were studied. Outcome was measured by expulsion rate, continuation rate, and incidence of dysfunctional uterine bleeding (DUB), Pelvic inflammatory disease (PID), failure rate and effect on puerperium.

Results: Expulsion rate in PPIUCD group was $8.75 \%$ while in interval IUCD group it was $1.25 \%$. Continuation rate following Postpartum intrauterine contraceptive device (PPIUCD) and interval IUCD insertion was $86.25 \%$ and $95 \%$ respectively. Incidence of bleeding per vaginum (menorrhagia) was $7.5 \%$ in PPIUCD group while $8.75 \%$ in interval IUCD group. There was one case $1.25 \%$ of PID in interval IUCD group while no case in PPIUCD was noted. Failure rate was nil in both the group. There was no effect on puerperium following PPIUCD insertion group during present study.

Conclusions: PPIUCD is an effective and safe spacing method of contraception as compared to interval IUCD insertion. There is no statistically significant change in incidence of expulsion rate, continuation rate and other complications in both the group.
\end{abstract}

Keywords: Continuation rate, Expulsion Rate, Failure rate, Incidence of DUB, Interval IUCD, PID, PPIUCD

\section{INTRODUCTION}

According to Family Welfare Statistics 2011, Current population of India is 1.21 billion. 5.7\% couples are effectively protected by using IUCD as a contraceptive measure. During the year 2010-11, 5.6 million IUCD insertion were reported as against 5.7 million in 2009-10. This shows decrease in acceptance rate of IUCD. Family planning is important not only for population stabilization, but it has been increasingly recognized as central tool to improve maternal and neonatal health.
The methods of contraception currently available in India can be broadly divided into two categories, spacing methods and permanent methods.

\section{Spacing methods}

These are the reversible methods of contraception to be used by couples who wish to have children in future. These includes

- Hormonal methods - oral/injectables

- Barrier methods - male/female condoms 
- Intra uterine contraceptive devices (IUCD)

\section{Permanent methods}

Male/female sterilization. According to DLHS-3 ${ }^{1}$, in India contraceptive use is $54 \%$ but only $2 \%$ of married women of reproductive age use IUCD. Despite the fact that the govt. offers the IUCD service free of cost and IUCD is one of the most effective and safe contraception methods, it still remains largely underutilized. In order to improve the acceptance of IUCD, Indian government has introduced PPIUCD insertion in national programme, as the couples are being more counselled during antenatal visits and after delivery.

As a contraceptive used during post-partum period, the IUCD has a distinct advantages. It is a reversible method. In addition, IUCD does not require regular user compliance. It is free from systemic side effects and does not affect breast feeding as seen with hormonal methods. It is also not coital dependent and there is no pain on insertion when used post-placentally ${ }^{2}$. No medical disease and drugs are contraindicated for insertion of IUCD, while oral contraceptive pills may be contraindicated in some diseases and taking some drugs.

Some of these advantages are also with the interval IUCD but due to high unmet need of contraception after delivery and huge number of institutional delivery provides a great opportunity for woman to gain access to PPIUCD. So acceptability and sustainability may be high for PPIUCD.

Studies show that conceptions within 24 months of a previous birth have a higher risk of adverse outcomes like abortions, premature labor, postpartum hemorrhage, low birth weight babies, fetal loss and maternal death ${ }^{3}$. So through NRHM, couples are being encouraged for PPIUCD insertion for birth spacing.

\section{Some side effects described below also limit the use of IUCD}

- Longer and heavier menstrual periods

- Bleeding or spotting between periods

- More cramps or pain during periods

- Does not protected against STIs and HIV

- Requires a trained health care provider to insert and remove the IUD May be expelled spontaneously

Several factors have limited the widespread use of the IUCD like misconceptions about the mechanism of action of the IUCD; history of negative publicity; misinformation about the risks of ectopic pregnancy, infection and infertility; lack of clinician training; and fears of litigation. ${ }^{4}$ Because of all these reasons mentioned above, acceptability of PPIUCD is low. Therefore, we had designed and implemented a study for better understanding of sustainability, effectiveness and safety of PPIUCD as compared with interval IUCD. Aim of current study was to compare interval IUCD and post partum IUCD insertion in terms of effectiveness and safety.

\section{METHODS}

A prospective observational cohort study was conducted by the Department of Obstetrics and Gynecology, GMERS Medical College and Hospital, Sola, Ahmedabad, Gujarat, India. Total study population was 160 women. They were divided in two groups, 80 women in each group. The study period is from August 2015 to April 2017.

\section{Sample size}

Sample size was calculated by below mention formula.

$\mathrm{n}=\mathrm{z}(\mathrm{p} 1 \mathrm{q} 1+\mathrm{p} 2 \mathrm{q} 2+1.28 \sqrt{2} \mathrm{PQ}) 2 /(\mathrm{p} 1-\mathrm{p} 2) 2$

$\mathrm{z}=1.96$ at $95 \%$ of confidence interval

$1.28=$ Power of study

$\mathrm{p}_{1=0.16}$

$\mathrm{q}_{1}=1-\mathrm{p}_{1}=0.84$

$\mathrm{p}_{2}=0.05$

$\mathrm{q}_{2}=0.95$

$\mathrm{p}=\mathrm{p}_{1+\mathrm{p} 2} 2=0.105$

$\mathrm{q}=1-\mathrm{p}=0.895$

so, $\mathrm{n}=160$ (sample size).

80 were allotted in each group

\section{Inclusion criteria}

For PPIUCD (as per NRHM guideline)

- Women willing to undergo IUCD

- Post placental

- Postpartum <48 hours

- During caesarean section.

For interval IUCD

- $\quad$ Anytime after 6 weeks following delivery

- Women willing to undergo IUCD insertion

- Who are eligible as per WHO medical eligibility criteria.

\section{Exclusion criteria}

For PPIUCD (as per NRHM guideline)

- Patient who does not give consent

- Patients with chorioamnionitis

- Patients with premature rupture of membranes (PROM)> 18 hours

- Patients with puerperal sepsis

- Patients with unresolved postpartum hemorrhage

- Patients with uterine anomaly

For interval IUCD

- Women who are not giving consent 
- Women were excluded as per the WHO MEC.

The National guidelines for IUCD Insertion were followed while selecting the patient. The clients were given information sheet (Annexure-2) and following which informed consent was taken for participation in study. All clients were assessed and detailed relevant history was taken and examination was carried out. Information was recorded in prescribed proforma. Patients were then taken for IUCD $(\mathrm{Cu}$ T 380A) insertion.

The steps followed for PPIUCD insertion and interval IUCD insertion were followed as per IUCD reference manual for AYUSH doctors, January-2014 module. Complaints of both the groups were asked, examinations were carried out and ultrasonography was conducted.

\section{Follow up}

Clients of PPIUCD were followed at one week, six weeks and at one year. Clients of interval IUCD were followed at 1 week, 1 month and at one year.

\section{RESULTS}

The comparison between post-partum and interval insertion of $\mathrm{Cu}-\mathrm{T}$ was done using the following indicators:

- Expulsion rate

- Continuation rate

- Incidence of PID and DUB

- Failure rate

- Effect on puerperium

Table 1: Age group distribution with PPIUCD and interval IUCD.

\begin{tabular}{|lll|llll|}
\hline Age group & PPIUCD & No & \% & Nnterval IUCD & \multicolumn{2}{l|}{ Total } \\
\hline $15-20$ & 5 & 6.25 & 10 & 12.5 & No & \% \\
\hline $21-25$ & 40 & 50 & 39 & 48.75 & 79 & 49.38 \\
\hline $26-30$ & 30 & 37.5 & 27 & 33.75 & 57 & 35.62 \\
\hline $31-35$ & 5 & 6.25 & 3 & 3.75 & 8 & 5.0 \\
\hline $36-40$ & 0 & 0 & 1 & 1.25 & 1 & 0.6 \\
\hline Total & 80 & $100 \%$ & 80 & $100 \%$ & 160 & $100 \%$ \\
\hline Mean age & 24.69 years SD-4.53 & 24.12 years SD- 4.197 & 24.4 years SD- 5.56 \\
\hline
\end{tabular}

Above table shows the relation of age and acceptance of IUCD in both the groups. In the present study most of the women belonged to age group between 21 to 25 years (49.38\%), followed by 26 to 30 years ( $35.62 \%)$, less than or equal to 20years $(9.38 \%)$ and more than 30 years $(5.62 \%)$.

The mean age of the study population was $24.4 \pm 5.56$ years. The youngest patient in study was 18 years and the oldest patient in study was 37 years. Majority of patients in my study belonged to third decade of life. Mean age of both the group was comparable which were $24.69 \pm 4.53$ years and $24.12 \pm 4.197$ years respectively.

Table 2: Parity distribution (\%) with PPIUCD and interval IUCD.

\begin{tabular}{|lll|}
\hline Parity & $\begin{array}{l}\text { PPIUCD } \\
\text { n=80 } \\
\text { Group A }\end{array}$ & $\begin{array}{l}\text { Interval IUCD } \\
\text { n=80 } \\
\text { Group B }\end{array}$ \\
\hline Primipara & $\begin{array}{ll}15(18.75 \%) \\
20(25 \%)\end{array}$ \\
\hline Multipara & $65(81.25 \%)$ & $60(75 \%)$ \\
\hline$\chi^{2}$ value- $0.914, \quad$ p value- $0.3390, \quad$ df- 1 \\
\hline
\end{tabular}

Table 2 shows parity distribution with PPIUCD and Interval IUCD insertion. In present study group A, $18.75 \%$ patients were primipara and $81.25 \%$ patients were multipara while in group B, $25 \%$ patients were primipara and $75 \%$ patients were multipara.

As shown in the Tables 3 PPIUCD and interval IUCD acceptance was higher in Multipara patients. However primpara also accepted PPIUCD and interval IUCD. With a p value of 0.3390 , it could be deciphered that parity was not statistically significant.

Table 3: Expulsion rate in PPIUCD and interval IUCD.

\begin{tabular}{|c|c|c|}
\hline $\begin{array}{l}\text { Type of } \\
\text { Insertion }\end{array}$ & PPIUCD $(n=80)$ & $\begin{array}{l}\text { Interval IUCD } \\
(\mathrm{n}=\mathbf{8 0})\end{array}$ \\
\hline Expelled & $7(8.75 \%)$ & $1(1.25 \%)$ \\
\hline Not Expelled & 73 & 79 \\
\hline
\end{tabular}

Below Table 3 shows expulsion rate in PPIUCD and interval IUCD group. Expulsion occurred in 7 cases $(8.75 \%)$ after PPIUCD insertion. Expulsion occurred in only 1 case $(1.25 \%)$ after interval insertions. Thus it 
suggests expulsion rate is more in PPIUCD insertion than interval IUCD which is statistically not significant ( $p$ $0.06)$.

Table 4: Continuation rate in PPIUCD and interval IUCD insertion at 1 year.

\begin{tabular}{|c|c|c|}
\hline $\begin{array}{l}\text { IUCD } \\
\text { continued }\end{array}$ & $\begin{array}{l}\text { PPIUCD } \\
(n=80)\end{array}$ & $\begin{array}{l}\text { Interval IUCD } \\
(\mathrm{n}=\mathbf{8 0})\end{array}$ \\
\hline Yes & $69(86.25 \%)$ & $76(95 \%)$ \\
\hline No & $11(13.75 \%)$ & $4(5 \%)$ \\
\hline$\chi^{2}$ value- 2 & $p v$ & 0.1037 \\
\hline
\end{tabular}

Above table shows continuation rate in PPIUCD and Interval IUCD insertion at 1 year. Above table suggest that Continuation rate is more in interval IUCD insertion (95\%) as compared to PPIUCD insertion (86.25\%). The data is statistically not significant $(p-0.1037)$

Table 5: Comparison of various complications in PPIUCD and interval IUCD group.

\begin{tabular}{|lll|}
\hline Complication & $\begin{array}{l}\text { PPIUCD } \\
(\mathbf{n = 8 0})\end{array}$ & $\begin{array}{l}\text { Interval IUCD } \\
(\mathbf{n = 8 0})\end{array}$ \\
\hline Menorraghia & $06(7.50 \%)$ & $07(8.75 \%)$ \\
\hline PID & 00 & $01(1.25 \%)$ \\
\hline Expulsion & $07(8.75 \%)$ & $01(1.25 \%)$ \\
\hline $\begin{array}{l}\text { Failure } \\
\text { (pregnancy) }\end{array}$ & 00 & 00 \\
\hline Perforation & 00 & 00 \\
\hline Total & $\mathbf{1 3 ( 1 6 . 2 5 \% )}$ & $\mathbf{0 9}(\mathbf{1 1 . 2 5 \% )}$ \\
\hline
\end{tabular}

Above table shows comparison of various complications in PPIUCD and Interval IUCD insertion group. Above table shows that in PPIUCD group complications occurred in 13 cases $(16.25 \%)$ while in interval IUCD group complications occurred in 09 cases (11.25\%). In PPIUCD, expulsion is most common complication while after interval IUCD insertion menorrhagia is most common complication.

\section{DISCUSSION}

Cochrane database systemic review, 2010 assessed the efficacy and feasibility of post-partum IUD insertion. ${ }^{5}$ In this review all randomized controlled trials that involved immediate post-partum (within ten minutes of placental expulsion) insertions of an IUD were studied. The review concluded that immediate post-partum insertion of IUDs appeared safe and effective.

However, expulsion rates appeared to be higher in postpartum than with interval insertion as likely in our study.

Mean age of study population was $24.69 \pm 4.53$ years in PPIUCD group and $24.12 \pm 4.197$ in interval IUCD group which was comparable to study conducted by Singh U et al. ${ }^{7}$ In a study by Srivastava et al mean age of study population was 31.66 years in PPIUCD group and 32.7 years in interval IUCD group. ${ }^{6}$ In the present study, most of the patients belonged to the age group of 21-25 years which was comparable to study conducted by Shrivastava et al and Singh U et al.

Table 6: Age distribution in various studies.

\begin{tabular}{|c|c|c|c|}
\hline Study & Year & $\begin{array}{l}\text { Mean age of } \\
\text { study in years }\end{array}$ & $\begin{array}{l}\text { Mean age of } \\
\text { study in years }\end{array}$ \\
\hline & & PPIUCD & Interval IUCD \\
\hline $\begin{array}{l}\text { Srivastava } \\
\text { et } \mathrm{al}^{6}\end{array}$ & 2013 & 31.66 & 32.7 \\
\hline $\begin{array}{l}\text { Singh U } \\
\text { et } \mathrm{al}^{7}\end{array}$ & 2017 & $27.6 \pm 2.8$ & $27.13 \pm 3.1$ \\
\hline $\begin{array}{l}\text { Present } \\
\text { study }\end{array}$ & 2017 & $24.69 \pm 4.53$ & $24.12 \pm 4.197$ \\
\hline
\end{tabular}

Table 7: Parity of patients in various studies.

\begin{tabular}{|c|c|c|c|}
\hline Study & Year & p value & \\
\hline Grimes et $\mathrm{al}^{5}$ & 2010 & 0.495 & Not significant \\
\hline Srivastava et $\mathrm{al}^{6}$ & 2013 & 0.358 & Not significant \\
\hline Mishra et $\mathrm{al}^{8}$ & 2014 & 0.419 & Not significant \\
\hline Present study & 2017 & 0.339 & Not significant \\
\hline
\end{tabular}

In present study, PPIUCD and interval IUCD acceptance was higher in Multipara patients. However primpara also accepted PPIUCD and interval IUCD. Present study is consistent with study of Grimes et al and Srivastava et al where they found higher acceptance in multiparous. 5,6 But it was not consistent with Mishra et al where acceptance was most common among primipara. ${ }^{8}$ Though $p$ value is more than 0.05 , which was statistically not significant.

Table 8: Expulsion rate in PPIUCD and interval IUCD in various studies.

\begin{tabular}{|c|c|c|c|}
\hline Study & Year & \multicolumn{2}{|c|}{ Expulsion rate (\%) } \\
\hline & & PPIUCD & Interval IUCD \\
\hline Gupta $\mathrm{A}$ et $\mathrm{al}^{9}$ & 2013 & $6.6 \%$ & $2.0 \%$ \\
\hline 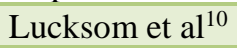 & 2014 & $0.0 \%$ & $5.95 \%$ \\
\hline Mohan $\mathrm{H}$ et $\mathrm{al}^{11}$ & 2015 & $5.5 \%$ & $5.0 \%$ \\
\hline Srivastava et $\mathrm{al}^{6}$ & 2016 & $2.30 \%$ & $0.9 \%$ \\
\hline Singh $\mathrm{U}$ et $\mathrm{al}^{7}$ & 2017 & $6.96 \%$ & $2.2 \%$ \\
\hline Present study & 2017 & $8.75 \%$ & $1.25 \%$ \\
\hline
\end{tabular}

In Gupta A et $a l^{9}$ and Singh $\mathrm{U}$ et $a l^{7}$ expulsion rate of PPIUCD were $6.6 \%$ and $6.96 \%$ respectively. In present study expulsion rate of PPIUCD was $8.75 \%$ which is comparable with above studies. In Mohan $\mathrm{H}$ et $a l^{11}$, Srivastava et $a l^{6}$ and Lucksom et $a l^{10}$ expulsion rate of PPIUCD were $5.5 \%, 2.30 \%$ and $0.0 \%$ respectively. In present study expulsion rate of PPIUCD was $8.75 \%$ which is not comparable with above studies. In Gupta A et al, Srivastava et al and Singh $U$ et al expulsion rate of Interval IUCD insertion were $2.0 \%, 0.9 \%$ and $2.2 \%$ respectively. ${ }^{6,7,9}$ In present study expulsion rate of Interval IUCD was $1.25 \%$ which is comparable with 
above studies. In Lucksom et al and Mohan $\mathrm{H}$ et al expulsion rate of Interval IUCD insertion were $5.95 \%$ and $5.0 \%$ respectively. ${ }^{10,11}$ In present study expulsion rate of Interval IUCD insertion was $1.25 \%$ which is not comparable with above studies. In Gupta A et al, Singh U et al, Mohan $\mathrm{H}$ et al and Srivastava et al expulsion rate higher in PPIUCD than Interval IUCD insertion group which was comparable with present study. ${ }^{6,7,9,11}$ While in Lucksom et al expulsion rate was higher in Interval IUCD group than PPIUCD group this was because focus training of doctors in PPIUCD insertion which was not comparable with our study. ${ }^{10}$ Below table shows in various studies continuation rate of PPIUCD group varies from $88 \%$ to $94.20 \%$ which was comparable with present study where continuation rate was $86.25 \%$. In various studies continuation rate of Interval IUCD insertion group varies from $81.81 \%$ to $92 \%$ which was comparable with present study where continuation rate was $95 \%$. In present study it was observed that continuation rate was more in interval IUCD insertion (95\%) as compare to PPIUCD insertion (86.25\%), though it was statistically not significant. $(\mathrm{p}=0.673)$ similarly Gupta $A$ et al observed that continuation rate was higher in interval IUCD group than PPIUCD group. ${ }^{9}(p=0.49)$ but it was not statistically significant. While Mohan et al, Srivastava et al and Singh $U$ et al showed higher continuation rate of PPIUCD groups than interval IUCD group although slight difference existed between the two groups but difference was not statistically significant. ${ }^{6,7,11}$

Table 9: Continuation rate in PPIUCD and interval IUCD in various studies.

\begin{tabular}{|lllll|}
\hline Study & Year & PPIUCD & Interval IUCD & P value \\
\hline Gupta A et al $^{\mathbf{1}}$ & 2013 & $90.0 \%$ & $92.0 \%$ & 0.49 \\
\hline Mohan H et al $^{11}$ & 2015 & $88.0 \%$ & $84.0 \%$ & 0.79 \\
\hline Srivastava et al & 2016 & $94.20 \%$ & $90.20 \%$ & $>0.05$ \\
\hline Singh U et al & 2017 & $88.23 \%$ & $81.81 \%$ & 0.49 \\
\hline Present study & 2017 & $86.25 \%$ & $95 \%$ & 0.6736 \\
\hline
\end{tabular}

Table 10: Comparative analysis of complications in both groups.

\begin{tabular}{|c|c|c|c|c|c|c|c|c|}
\hline \multirow[t]{2}{*}{ COMPLICATIONS } & \multicolumn{2}{|c|}{ Gupta $A$ et al ${ }^{9}$} & \multicolumn{2}{|c|}{ Srivastava et $a^{6}$} & \multicolumn{2}{|c|}{ Singh $\mathrm{U}$ et $\mathbf{a l}^{7}$} & \multicolumn{2}{|c|}{ present study } \\
\hline & $\begin{array}{l}\text { PPIUCD } \\
(\mathbf{n}=\mathbf{3 0 0})\end{array}$ & $\begin{array}{l}\text { Interval } \\
\text { IUCD } \\
(\mathbf{n}=150)\end{array}$ & $\begin{array}{l}\text { PPIUCD } \\
(n=347)\end{array}$ & $\begin{array}{l}\text { Interval } \\
\text { IUCD } \\
(n=114)\end{array}$ & $\begin{array}{l}\text { PPIUCD } \\
(\mathbf{n}=150)\end{array}$ & $\begin{array}{l}\text { Interval } \\
\text { IUCD } \\
(\mathbf{n}=\mathbf{1 5 0})\end{array}$ & $\begin{array}{l}\text { PPIUCD } \\
(\mathbf{n}=\mathbf{8 0})\end{array}$ & $\begin{array}{l}\text { Interval } \\
\text { IUCD } \\
(\mathbf{n = 8 0})\end{array}$ \\
\hline Menorraghia & $4.33 \%$ & $5.3 \%$ & $7.2 \%$ & $21.9 \%$ & $2.66 \%$ & $7.9 \%$ & $7.5 \%$ & $8.75 \%$ \\
\hline Expulsion & $4.33 \%$ & $2.0 \%$ & $2.3 \%$ & $2.9 \%$ & $6.96 \%$ & $2.2 \%$ & $8.75 \%$ & $1.25 \%$ \\
\hline PID & $0.0 \%$ & $1.2 \%$ & $1.2 \%$ & $5.3 \%$ & $0.0 \%$ & $0.0 \%$ & $0 \%$ & $1.25 \%$ \\
\hline Abdominal pain & $2.33 \%$ & $2.0 \%$ & $2.9 \%$ & $12.2 \%$ & $1.3 \%$ & $2.9 \%$ & $5.00 \%$ & $2.5 \%$ \\
\hline Discharge $\mathrm{p} / \mathrm{v}$ & $4.0 \%$ & $4.0 \%$ & - & - & $2.7 \%$ & $5.8 \%$ & $7.5 \%$ & $3.75 \%$ \\
\hline
\end{tabular}

\section{CONCLUSION}

From the above study we came to the conclusion that PPIUCD is an effective spacing method of contraception as compared to interval IUCD insertion PPIUCD insertion is safe when compared to interval IUCD insertion however morbidity was observed more in PPIUCD as compared to interval IUCD insertion, though the data is not statistically significant. There is no statistically significant change in incidence of expulsion rate, continuation rate and menorrhagia in PPIUCD group as compared to interval IUCD insertion. There is no effect of PPIUCD on puerperium.

\section{ACKNOWLEDGMENTS}

Authors would like to thank department of Obstetrics and Gynecology, GMERS Medical College and Hospital,
Sola, Ahmadabad, Gujarat, for all the kind support and thanks to all the participants for their cooperation.

Funding: No funding sources

Conflict of interest: None declared

Ethical approval: The study was approved by the Institutional Ethics Committee

\section{REFERENCES}

1. Ram F, Ladusingh L, Paswan B. IUCD Reference Manual for Medical Officers and Nursing Personnel, /IIPS, Mumbai, DLHS-3(2007-2008)/Sep 3, 2013.

2. Shukla M, Qureshi S, Chandrawati. Post-placental intrauterine device insertion - a five year experience at a tertiary care centre in north India Department of Obstetrics and Gynaecology, KG Medical 
University, Lucknow, India Indian J Med Res. 2012;136(3):432-5.

3. Bill and Melinda Gates Foundation, PPIUCD Reference Manual, Ministry of Health and Family Welfare, Govt. of India, 2010;1-4.

4. Stanwood NL, Garrett JM, Konrad TR. Obstetriciangynecologists and the intrauterine device: a survey of attitudes and practice. Obstet Gynecol. 2002;99:275.

5. Grimes DA, Lopez LM, Schulz KF, Van Vliet HAAM, Stanwood NL. Immediate post-partum insertion of intrauterine devices. Cochrane Database Syst Rev. 2010;(5):CD003036.

6. Srivastava S, Bano I. Evaluation of PPIUCD versus Interval IUCD Insertion, Acceptability of PPIUCD versus Interval IUCD Insertion. IJSR. 2016.

7. Singh U, Sonkar S. Comparative evaluation of postpartum IUCD versus interval IUCD Int J Reprod Contracept Obstet Gynecol. 2017;6(4):1534-8.

8. Mishra N, Dalal N, Joshi V. Intrauterine device insertion during caesarean section- a boon for rural women. IOSR-JDMS. 2013;8(3):21-3.
9. Gupta A, Verma A, Chauhan J. Evaluation of PPIUCD versus interval IUCD (380) insertion in a teaching hospital of Western U.P. Int J Reprod Contracept Obstet Gynecol. 2013;2(2):204-20.

10. Lucksom. Comparative study of interval versus postpartum $\mathrm{Cu}-\mathrm{T}$ insertion in a central referral hospital of North East India Int J Reprod Contracept Obstet Gynecol. 2015;4(1):47-51.

11. Mohan H, Ramappa R, Sandesh M, Akash BK. PPIUCD versus interval IUCD (380a) insertion: a comparative study in a referral hospital of Karnataka, India. Int J Repro Contracept Obstet Gynecol. 2015;4(6):1730-2.

Cite this article as: Godhani $\mathrm{H}$, Patel D. Evaluation of post partum intrauterine contraceptive device versus interval IUCD insertion. Int J Reprod Contracept Obstet Gynecol 2019;8:3285-90. 